Acessibilidade formacional: a percepção profissional

na inclusão da pessoa com deficiência intelectual no lazer

\author{
GIRARDI, Vania Lucia (Brasil, Paraná, Curitiba) ${ }^{1 *}$ \\ RECHIA, Simone Aparecida (Brasil, Paraná, Curitiba) ${ }^{1 * *}$ \\ TSCHOKE, Aline (Brasil, Paraná, Curitiba) ${ }^{2^{t \star *}}$ \\ ${ }^{1}$ Universidade Federal do Paraná \\ ${ }^{2}$ Instituto Federal do Paraná \\ ORCID ID: https://orcid.org/0000-0002-9449-2434* \\ ORCID ID: https://orcid.org/0000-0002-2145-252X \\ ORCID ID: https://orcid.org/0000-0003-0490-4675**
}

\begin{abstract}
Resumo
Este artigo objetiva discorrer sobre a concepção de acessibilidade para as práticas no tempo/espaço de lazer da pessoa com deficiência intelectual na cidade de Curitiba, Paraná. A metodologia foi qualitativa com dados coletados através de entrevistas semiestruturadas abertas com seis gestores da Prefeitura Municipal de Curitiba, materiais de divulgação e informações disponíveis no site da prefeitura no período de 2013 a 2016. A análise aponta diversas barreiras enfrentadas por pessoas com deficiência intelectual no acesso aos bens e serviços públicos de lazer da prefeitura. Evidencia-se que, para a superação da barreira "formacional", torna-se necessária a formação profissional continuada e o conhecimento científico sobre pessoas com deficiência intelectual, somados ao olhar humano sensível, para que leis e ações nas políticas públicas de atendimento às pessoas com deficiência intelectual sejam efetivamente implementadas.
\end{abstract}

\title{
Palavras-chave
}

Acessibilidade. Formação profissional. Lazer. Deficiência intelectual.

\section{Formational acessibilty: the profissional perception in the inclusion of people with intellectual disability}

\begin{abstract}
This article objectify expatiate the conception of accessibility for practices in the time / space of leisure of the person with intellectual disability in the city of Curitiba, Paraná. This research was based in a qualitative method and data were collected through semi-structured interviews with 06 managers of the City Hall of Curitiba, analysis of dissemination materials and information available on the City Hall website between the years of 2013 to 2016 . This analysis points to many barriers faced by people with intellectual disability in accessing their rights and public leisure services at City Hall. It is evident that, in order to overcome the "formational" barrier, it is necessary to have continued professional qualification and scientific knowledge about people with intellectual disability in addition to a sensitive human outlook about them, so that laws and practices of public policies services for people with intellectual disability are effectively implemented.
\end{abstract}

\section{Keywords}

Accessibility. Leisure. Professional qualification. Intellectual disability. 


\title{
Accesibilidad formacional: la percepción profesional en la inclusión de la persona con discapacidad intelectual en el ocio
}

\begin{abstract}
Resumen
Este artículo tiene como objetivo discutir la concepción de accesibilidad a las prácticas en el espacio de tiempo / ocio de personas con discapacidad intelectual en la ciudad de Curitiba, Paraná. La metodología fue cualitativa con datos recopilados a través de entrevistas abiertas semiestructuradas con seis gerentes del Ayuntamiento de Curitiba, materiales de difusión e información disponibles en el sitio web del ayuntamiento de 2013 a 2016. El análisis señala varias barreras que enfrentan las personas con discapacidad intelectual en la ciudad, acceso a bienes públicos y servicios de ocio del ayuntamiento. Es evidente que, para superar la barrera "formacional", es necesario continuar la formación profesional y el conocimiento científico sobre las personas con discapacidad intelectual, sumados a la sensible mirada humana, para que las leyes y acciones en las políticas públicas de atención a las personas con discapacidad intelectual se implementen efectivamente.
\end{abstract}

\section{Palabras clave}

Accesibilidad. Formación profesional. Ocio. Discapacidad intelectual.

\section{INTRODUÇÃO}

O presente trabalho se originou de uma categoria de análise de dissertação de mestrado que trata sobre o lazer e a inclusão de pessoas com deficiência intelectual (DI) na cidade de Curitiba, Paraná. A análise teve como objetivo discorrer acerca de barreiras e facilitadores para as práticas tempo/espaço/lazer voltadas para o lazer da pessoa com DI na cidade de Curitiba a partir da concepção de acessibilidade por parte dos gestores da Prefeitura Municipal de Curitiba (PMC).

Em Curitiba, segundo dados do Instituto Brasileiro de Geografia (IBGE, 2010), para uma população de 1.751,970, havia aproximadamente 300.000 pessoas com deficiência, das quais 21.880 pessoas com DI. As demandas que envolvem a acessibilidade das pessoas com DI decorrem de necessidades encontradas no cotidiano, como comunicar-se, ter autonomia para fazer escolhas, autocuidar-se, locomover-se pela cidade com transporte público, o que pode se tornar um obstáculo para essas pessoas, estabelecendo uma dependência dos familiares ou responsáveis. Desse modo, diferentes barreiras e facilitadores foram apontados pelos gestores, especificamente para o DI. 
Para auxiliar na compreensão das especificidades da DI, utilizaremos a definição da American Association on Intellectual and Developmental Disabilities (AAIDD), em sua 11aㅡ edição, que considera que "[...] a deficiência tem origem antes dos 18 anos e é caracterizada por limitações significativas tanto no funcionamento intelectual quanto no comportamento adaptativo, expresso nas capacidades adaptativas conceituais, sociais e práticas" (AAIDD, 2010, p. 1).

Para pessoas com DI, é compreensível que o conceito de acessibilidade seja diferente daquele atribuído às demais deficiências por ter outras especificidades. De acordo com Millecamps (2010), uma pessoa com DI poderá ter certas dificuldades para: adaptar-se a mudanças imprevistas; avaliar a importância relativa às informações disponibilizadas; compreender o ambiente imediato ou alargado; concentrar-se por longos períodos; dominar a aritmética mental e o raciocínio lógico; dominar a leitura; dominar a escrita; executar rapidamente uma tarefa; exprimir-se; fixar a atenção; localizar-se no espaço; localizar-se no tempo; mobilizar energia; pedir ajuda espontaneamente; perceber os conceitos gerais e abstratos; perceber o modo de utilização das diversas aparelhagens; tratar e memorizar as informações orais e sonoras; e utilizar dinheiro.

Sobre essa questão, na visão dos gestores, os principais pontos relatados foram que os profissionais e as pessoas que vão trabalhar com pessoas com DI precisam ter conhecimento e estar preparados para recebê-los, adaptando-se às suas especificidades de acessibilidade.

A acessibilidade é um direito da pessoa com DI que ultrapassa barreiras físicas ou arquitetônicas. A Lei Brasileira de Inclusão (LBI) - Lei no 146/2015 - aponta as diversas barreiras para a acessibilidade, descritas como qualquer entrave, obstáculo, atitude ou comportamento que limite ou impeça a participação social da pessoa, bem como o gozo, a fruição e o exercício de seus direitos à acessibilidade, à liberdade de movimento e de expressão, à comunicação, ao acesso à informação, à compreensão, à circulação com segurança, entre outros, podendo ser urbanísticas, arquitetônicas, nos transportes, nas comunicações e na informação, atitudinais e tecnológicas, consoante artigo $3^{\circ}$ da LBI.

Entre as barreiras já identificadas na LBI, consideramos que, para a pessoa com DI, é fundamental romper com as atitudinais, eliminando, portanto, "[...] atitudes ou 
comportamentos que prejudiquem a participação social da pessoa com deficiência em igualdade de condições e oportunidades com as demais pessoas", conforme ainda o artigo $3^{\circ}$ da referida lei.

O artigo 42 da LBI prevê que "[...] a pessoa com deficiência tem direito à cultura, ao esporte, ao turismo e ao lazer em igualdade de oportunidades às demais pessoas, sendo-Ihe garantido o acesso". Segundo o artigo 43 da referida lei, "[...] o poder público deve promover a participação da pessoa com deficiência em atividades artísticas, intelectuais, culturais, esportivas e recreativas, com vistas ao seu protagonismo [...]" e "[...] assegurar acessibilidade nos locais de eventos prestados por pessoa ou entidade envolvida na organização das atividades" (BRASIL, 2015, art. 3º).

Desse jeito, a acessibilidade para pessoas com DI envolve conhecimento de suas necessidades, bem como atitudes que não subestimem suas potencialidades por parte de pessoas de sua convivência, ou seja, família, professores, profissionais das diversas áreas, interagindo e mediando o aprendizado, para que a inclusão seja possível nos diversos espaços, bens e serviços comuns a todos os cidadãos, a exemplo dos programas de esporte e lazer da cidade ofertados pela PMC. Dessa forma, para incluir pessoas com DI em programas e ações da PMC, é necessária uma atenção especial e formação continuada dos profissionais que as recebem.

$\mathrm{Na}$ análise, obtivemos diferentes concepções dos gestores sobre acessibilidade, o que solicita refletir sobre a formação profissional de quem atende a esse público nos programas ofertados pela PMC. A questão da acessibilidade está diretamente envolvida no "receber essas pessoas", elencando, dessa maneira, uma barreira a ser vencida: a da formação, que aqui será denominada "formacional". Essa barreira foi categorizada neste trabalho dentro de uma barreira atitudinal, ligada aos preconceitos e estereótipos e à mediação do profissional que interfere diretamente na inclusão da pessoa com DI nos programas de esporte e lazer desenvolvidos pela PMC. Nesse contexto, procuramos analisar a concepção de acessibilidade dos gestores diante da diferenciação que é dada à pessoa com DI.

Para a pessoa com DI, o lazer, direito garantido na LBI, "[...] merece tratamento sério [...], não como simples fator de amenização [...] para a vida, mas como questão mesmo de [...] sobrevivência do humano no homem" (MARCELLINO, 2002, p. 17). Nesse sentido, os dados desta pesquisa podem contribuir no que tange à identificação 
das necessidades de acessibilidade no processo inclusivo de pessoas com DI em programas e espaços públicos de lazer da cidade.

\section{METODOLOGIA}

Esta pesquisa teve cunho qualitativo, caracterizada por trabalhar com o universo dos significados, dos motivos, das aspirações, das crenças, dos valores e das atitudes, e esse "[...] conjunto de fenômenos humanos é entendido aqui como parte da realidade social" (MINAYO, 2010, p. 21). De caráter exploratório, foi utilizada como instrumento de pesquisa a observação participante, assim a pesquisa avançou para uma pesquisa-ação, pois, "[...] além da participação, supõe uma forma de ação planejada de caráter social, educacional, técnico ou outro, que nem sempre se encontra em propostas de pesquisa participante" (THIOLLENT, 1986, p. 7).

Nesse tipo de pesquisa, "[...] os pesquisadores desempenham um papel ativo no equacionamento dos problemas encontrados, no acompanhamento e na avaliação das ações desencadeadas em função dos problemas" (THIOLLENT, 1986, p. 15). Dessa forma, Freire (1990, p. 35) aponta que, "[...] no uso de instrumentos de pesquisa, a minha opção deve ser libertadora, se a realidade se dá a mim não como algo parado, imobilizado, posto aí, mas na relação dinâmica entre objetividade e subjetividade".

Foi realizada uma análise interpretativa, na qual foi adotada a estratégia de triangulação dos dados, que enriquece e complementa ainda mais o conhecimento, buscando atender aos objetivos propostos (FLICK, 2009), com diferentes métodos de coleta de dados (GÜNTHER; ELALI; PINHEIRO, 2011).

A pesquisa foi realizada em Curitiba, capital do Paraná, e o objeto de estudo se referiu às práticas cotidianas de lazer dos participantes do grupo Amigos do Handebol, dentro e fora do espaço escolar, e as ações efetivadas nas políticas públicas de inclusão voltadas para o lazer na cidade de Curitiba em 2016.

A população da pesquisa foi constituída por: seis gestores(as), servidores públicos que trabalham na PMC, dos quais cinco trabalham na Secretaria Municipal do Esporte, Lazer e Juventude (SMELJ) e um trabalha na Secretaria Especial dos Direitos da Pessoa com Deficiência (SEDPcD); quatro pessoas da equipe/pedagógica que trabalham nas escolas de educação especial dos referidos integrantes do grupo Amigos 
do Handebol; 13 responsáveis pelos integrantes do referido grupo (pessoas da família ou responsáveis legais); 14 integrantes do grupo suscitando anteriormente, composto por jovens/adultos com diagnóstico de DI, com idade entre 18 e 56 anos, em 2016, alunos e ex-alunos de escolas de educação especial de Curitiba. Ao todo, foram entrevistadas 37 pessoas. Os gestores foram selecionados a partir da participação direta em ações promovidas pela PMC voltadas para pessoas com deficiência.

A definição dos participantes da pesquisa foi feita pelo vínculo profissional da pesquisadora, que atua como professora de Educação Física em uma escola de educação especial na cidade de Curitiba desde 1997. Os dados foram fornecidos em contato direto com quatro escolas de educação especial, gestores e responsáveis/famílias e com os 14 integrantes do referido grupo inscritos na equipe masculina de handebol de DI. Esses representaram a cidade de Curitiba no 4ํ Jogos Abertos Paradesportivos do Paraná (Parajaps) em 2015.

Em março de 2016, a pesquisadora entrou em contato por telefone com os responsáveis e integrantes do grupo Amigos do Handebol, as escolas dos participantes e os gestores da PMC, para esclarecer, convidar, informar e solicitar autorização para participação na pesquisa e convidar os Amigos do Handebol a comparecerem aos encontros que aconteceram nos meses de abril a novembro de 2016, aos sábados, das 9h30 às 10h30, na Praça Brigadeiro do Ar Mário Calmon Eppinghaus. Ao todo, ocorreram dez encontros na Praça Eppinghaus, um encontro no Parque São Lourenço e uma participação nos Jogos Paradesportivos de Curitiba. A pesquisadora participou da organização dos encontros, informando os integrantes do grupo e responsáveis através do grupo formado no WhatsApp.

Os integrantes do grupo Amigos do Handebol são pessoas com diagnóstico de DI que foram convidados a participar da pesquisa acompanhados de seus responsáveis. Antes da entrevista, foi explicado o Termo de Consentimento Livre e Esclarecido (TCLE), detalhando a participação deles na pesquisa. Após a aprovação do Comitê de Ética da Saúde da Universidade Federal do Paraná (UFPR) e do Comitê de Ética (CEP) da SMELJ, foram realizadas as entrevistas - semiestruturadas, com perguntas abertas e fechadas voltadas ao tema da pesquisa. Os registros e a coleta de dados foram feitos em locais e horários indicados pelos participantes, nos meses de setembro, outubro e novembro de 2016, com gravação de áudio. 
$\mathrm{Na}$ categoria de análise que originou este trabalho, foram entrevistados cinco gestores(as) da SMELJ e um(a) gestor(a) da SEPCD - com visita da pesquisadora às dependências da SMELJ e da SEDPCD, em horário e local (sala de trabalho com mesas e cadeiras) definidos por eles - para levantar dados sobre as políticas públicas de inclusão voltadas para o lazer da pessoa com DI na cidade de Curitiba. Os gestores foram esclarecidos antes da entrevista sobre o que é o grupo Amigos do Handebol.

Para as entrevistas semiestruturadas, após a aprovação pelo CEP envolvendo seres humanos, setor de Ciências da Saúde da UFPR, Parecer CEP/SD-PB o 1752036 e Certificado de Apresentação para Apreciação Ética (CAAE), foram obtidas as autorizações necessárias e coletadas as assinaturas dos participantes em duas vias do TCLE: gestores. As entrevistas foram registradas com um gravador de voz Sony T-Mark ICD-PX240 e transcritas posteriormente na íntegra, com o intuito de preservar as ideias e sentidos originais das falas dos entrevistados.

Os dados coletados foram sistematizados e os participantes foram codificados para análise do conteúdo das entrevistas, que neste trabalho analisou gestores da PMC: G1 (Esporte), G2 (Centro de Referência Qualidade de Vida e Movimento - CRQVM), G3 (Portal do Futuro), G4 (Lazer), G5 (Regional Matriz), G6 (Secretaria Especial dos Direitos da Pessoa com Deficiência - SEDPcD).

As entrevistas foram realizadas após os participantes terem assinado o TCLE. As questões éticas têm como parâmetros a Resolução no 466, de 12 de dezembro de 2012, do Conselho Nacional de Saúde, do Ministério da Saúde (MS), que dispõe diretrizes e normas regulamentadoras para pesquisas envolvendo seres humanos. $O$ projeto de dissertação foi submetido, avaliado e aprovado pelo Comitê de Ética da SMELJ de Curitiba e pelo Comitê em Pesquisa da Saúde (CEP/SD) da UFP.

Para a análise, foram levantadas quatro categorias temáticas a posteriori a partir das falas dos entrevistados. Nesse recorte, foi destacada a categoria "formacional": (in)visibilidade da pessoa com DI, bem como a possibilidade de empoderamento pelo lazer. A categoria analisada evidencia as questões de acessibilidade na concepção de gestores perante $O$ atendimento de pessoas com DI. Foram realizadas as falas de entrevistas com os gestores ${ }^{1}$ com três questões: (A) O que é acessibilidade? (B) O que é

Foram entrevistados cinco gestores da SMELJ no ano de 2016 e uma gestora da SEDPcD.

Educação \& Formação, Fortaleza, v. 5, n. 13, p. 95-112, jan./abr. 2020

DOI: https://doi.org/10.25053/redufor.v5i13.1180

http://seer.uece.br/redufor 
acessibilidade para a pessoa com DI? (C) como é a acessibilidade para a pessoa com DI em Curitiba?

Com isso, foi realizada uma análise interpretativa com descrição dos dados e apresentação dos resultados encontrados de forma crítica e reflexiva sobre a concepção de acessibilidade voltada para o lazer e inclusão de pessoas com DI em Curitiba.

\section{RESULTADOS E DISCUSSÃO}

Para a maioria dos gestores, a questão do que seja acessibilidade se diferencia de acessibilidade para o $\mathrm{DI}$, o que se compreende, considerando que essas pessoas apresentam especificidades que as diferenciam das demais pessoas. Para tanto, foi trilhado um percurso que envolve as questões de acessibilidade para a pessoa com DI evidenciadas com a invisibilidade e a formação profissional para atender às demandas das pessoas com DI.

As questões de acessibilidade que envolvem as barreiras de informação e as atitudinais para com a DI ficaram evidenciadas no depoimento do Gestor 4:

[...] para as pessoas com deficiência intelectual, há a necessidade de dar acesso, porém hoje o maior acesso que eu vejo é para a pessoa na questão visual e motora no município de Curitiba. Em relação à acessibilidade em atividades, os programas desenvolvidos deveriam ter acolhimento e atividades acessíveis às pessoas com deficiência na forma do trato $[. .$.$] .$

Sobre acessibilidade em geral (A), foram identificadas nas falas dos gestores todas as formas de barreiras classificadas na LBI (urbanísticas; arquitetônicas; transportes; comunicação e informação; atitudinais; tecnológicas). Quanto ao que é acessibilidade para o DI (B), os gestores apontaram duas barreiras: atitudinais e de comunicação e informação. Sobre como é a acessibilidade para o Dl em Curitiba (C), um gestor não soube informar, quatro apontaram "atitudinal" e um apontou "informação e comunicação". Assim sendo, informação é um fator importante para que as ações da PMC possam ser conhecidas pela população em geral. Segundo Certeau (2014, p. 260), "[...] o grande silêncio das coisas muda-se no seu contrário através da mídia". Ficou evidenciada a necessidade de divulgação, estrutura e capacitação profissional através de formação de professores da SMELJ mediante a fala de G4: 


\begin{abstract}
Primeiramente temos que divulgar esse acesso das crianças, essa inclusão das pessoas com deficiência nas nossas atividades, dar maior estrutura, ter equipamento apropriado para receber a pessoa com deficiência, ter pessoas qualificadas para receber as pessoas com deficiência.
\end{abstract}

Nas políticas públicas de inclusão de Curitiba gestão 2013-2016, observaram-se ações para a questão estrutural de acessibilidade, como as barreiras físicas, arquitetônicas e sensoriais voltadas mais para pessoas com deficiência visual e deficiência física. Nesse sentido, o conceito de acessibilidade plena, conforme Duarte e Cohen (2014, p. 143), parte do princípio de que:

[...] apenas uma boa acessibilidade física não é suficiente para que o espaço possa ser compreendido e de fato usufruído por todos. A Acessibilidade Plena significa considerar mais do que apenas a acessibilidade em sua vertente física e prima pela adoção de aspectos emocionais, afetivos e intelectuais indispensáveis para gerar a capacidade do lugar de acolher seus visitantes e criar aptidão no local para desenvolver empatia e afeto em seus usuários.

Para uma pessoa com DI, a acessibilidade esbarra na segurança e autonomia, o que torna necessária uma mudança no agir, na atitude, no entendimento e no repasse da informação. Segundo Lefebvre (2001, p. 22), “[...] a vida urbana pressupõe encontros, confrontos das diferenças, conhecimentos e reconhecimentos recíprocos (inclusive no confronto ideológico e político) dos modos de viver, dos 'padrões' que coexistem na cidade".

As barreiras de informação e atitudinais devem ser sanadas para que essas pessoas tenham garantida a acessibilidade aos diversos bens sociais e culturais, entre eles o lazer. Nas cidades, o respeito à diferença no uso dos espaços urbanos requisita entender que um espaço ou um serviço só pode ser inclusivo para a pessoa com deficiência quando, além da acessibilidade, houver o acolhimento por parte dos cidadãos.

Presente na fala dos gestores da PMC, uma das questões determinantes para 0 atendimento da pessoa com DI na cidade é a invisibilidade desses sujeitos. Segundo G3: "Somente depois da visibilidade que se pode falar de política pública. Enquanto você não vê o sujeito, ele continua não existindo".

Desse modo, são necessárias ações que revelem o público em pauta como usuário dos espaços públicos para que os gestores consigam identificar suas demandas 
e colocar em prática ações humanas e inclusivas. Assim, a visibilidade pode ter duplo sentido, como a falta de demanda pela ausência de pessoas com DI nos espaços e programas da PMC e a falta de visibilidade das características de pessoas com DI que não apresentam "sinais" no aspecto físico. As que apresentam "sinais" no aspecto físico, a exemplo da Síndrome de Down², tornam mais evidente a sua condição, o que revela as diferenças, visíveis ou não, conforme a fala de G3 (grifou-se):

\begin{abstract}
Acho que uma dificuldade mesmo é a questão da visibilidade, porque as pessoas usam termos pejorativos, que eu não vou repetir aqui, mas vocês devem conhecer aos milhões, como se fosse uma bobagem, bobo, não está prestando atenção, desatento, talvez essa seja a deficiência mais difícil de detectar, inclusive na sala de aula a gente vê isso. É difícil as pessoas perceberem que é uma deficiência, acham que é preguiçoso ou que não está com vontade; a gente sempre fica atribuindo outras situações e acaba não investigando realmente a causa, por ignorância, no sentido amplo da palavra, realmente por ignorar esse tipo de deficiência.
\end{abstract}

Quanto à visibilidade da pessoa com DI, há pontos relevantes para se analisar. Primeiro, a falta de conhecimento e formação por parte dos profissionais no reconhecimento das características da deficiência, levando a um despreparo no atendimento de suas especificidades. Segundo, a falta de visibilidade das pessoas com DI em não se apropriarem dos espaços e participarem dos programas da PMC que poderiam ser usufruídos por elas, restringindo a demanda desse público específico e relativizando a necessidade de estruturação de serviços e recursos humanos para atendê-lo. Terceiro, a falta de conhecimento de direitos por parte da população em geral, incluindo gestores, profissionais, famílias e eles próprios na condição de passividade na luta por seus direitos.

Também sobre as informações de direitos e símbolos sobre a DI, um dos gestores indica também que ainda não tem a mesma visibilidade, o que fica evidenciado nas falas dos gestores G3 e G6 (grifou-se):

A deficiência intelectual ainda não tem a mesma visibilidade, até pelos símbolos [...]. O símbolo da pessoa com deficiência é o cadeirante, [...] especialmente com a visibilidade, porque só depois da visibilidade que se pode falar em políticas públicas; enquanto você não vê o sujeito, ele continua não existindo.

2 "A Síndrome de Down é causada pela presença de três cromossomos 21 em todas ou na maior parte das células de um indivíduo (Movimento Down)". Disponível em: http://www.movimentodown.org.br/ sindrome-de-down/o-que-e/.

Educação \& Formação, Fortaleza, v. 5, n. 13, p. 95-112, jan./abr. 2020

DOI: https://doi.org/10.25053/redufor.v5i13.1180

http://seer.uece.br/redufor 
$\mathrm{Na}$ fala ficou evidenciado que, para o atendimento de pessoas com $\mathrm{DI}$, a formação profissional e a visão humana de acolhimento desse sujeito devem ser preponderantes. Portanto, não basta o profissional ser acessível possuindo formação específica na área de pessoas com deficiência, precisa ter dimensão humana e um olhar sensível, o que fica evidente na fala dos entrevistados.

Os programas que desenvolvemos na área da dança, do ciclismo, da recreação, da ludicidade, estão abertos para poder acolher essa pessoa com deficiência durante os eventos, por meio de atividades que nos permitam interagir em conjunto. Inclusive nós tentamos desenvolver a inclusão em nossos projetos, no Projeto Ciclo Lazer, em que há o skate adaptado, que atende a crianças com problemas de diversos níveis, tanto intelectual quanto motor. [...] A criança é colocada num sistema de ganchos e consegue experimentar, vivenciar a estrutura do skate. Porque o deficiente intelectual muitas vezes não tem equilíbrio, noção de tempo e espaço, então por isso também ele participa do skate adaptado. (G4).

Já para o profissional atender a uma pessoa com DI, a forma de passar as informações e a maneira de intermediar podem demandar um tempo maior na comunicação, pois muitas delas não sabem ler nem escrever, tornando necessário haver algum indicativo mais visual. A linguagem precisa ser decodificada, interpretando a forma de se expressar da pessoa com DI com diferentes estratégias.

Sobre esse ponto, Hagg (2016) destaca que, para a pessoa com DI, a linguagem não deve ser entendida apenas como forma de expressar o pensamento e coloca a interação através da mediação do profissional que está avaliando a pessoa com DI como ponto crucial para se compreender as demandas dessas pessoas. Segundo o autor:

É preciso perceber que as práticas de linguagem não apenas compõem as práticas sociais, como ainda são o principal meio de construção, troca e cristalização das representações, e estas, por sua vez, orientam as práticas sociais. É por meio da atividade de linguagem, atravessada pelas representações, que ocorrem os processos de interação que promovem (ora mais, ora menos) o desenvolvimento humano. Eis porque é necessário ressignificar as representações sobre a pessoa com deficiência intelectual. (HAGG, 2016, p. 203).

Portanto, compreender a pessoa com DI é fundamental para um bom encaminhamento de suas práticas.

Analisando as respostas dos gestores, percebeu-se uma barreira, aqui definida como "formacional", não descrita na LBI nem na literatura, que está vinculada à 
formação profissional com conhecimento científico, e a atitude "humana", no acolhimento, na alteridade, na solidariedade no compromisso, o que, para Paulo Freire (1988, p. 19), “[...] comprometer-se com a desumanização é assumi-la e, desumanizarse também". Desse modo, no pensamento de Paulo Freire (1988), quanto mais a pessoa se capacita como profissional, quanto mais sistematiza experiências, quanto mais se utiliza do patrimônio cultural, que é de todos e ao qual todos devem servir, mais aumenta sua responsabilidade com os homens.

Ser acolhedor e dar atenção é humano, mas, para tratar com equidade, são necessárias estratégias de ensino diferenciadas para a pessoa com DI. O profissional precisa ter conhecimento científico e interagir mediando com criatividade para encontrar soluções e compreender que atender a uma pessoa com DI significa "[...] refazer a maneira de vivenciar as coisas" (G6), pois esse sujeito demanda atenção maior, sendo necessário dedicar um tempo diferenciado no "trato" com ele.

Em relação às barreiras e dificuldades, acredito que seja um pouco do profissional, que deve estar capacitado e entender do que se trata, então, quando chega um deficiente intelectual leve, a gente avalia e percebe que é fácil o atendimento, mas, se é um pouquinho mais severo, o profissional não está preparado para atender. Acredito que essa seja a barreira, a barreira não é do deficiente, é do profissional que está recebendo. (G2, grifou-se).

Evidencia-se na fala de G2 a barreira "formacional". Ele elenca fatores e valores que demandam conhecimento e atitude desse profissional: a formação mais a atitude de forma indissociável. O "eu" profissional, com conhecimento científico, não pode se dissociar do "eu" humano, que recebe, vê e acolhe. Sobre esse tema, Paulo Freire (1988, p. 19) afirma que: "[...] se nos interessa analisar o compromisso do profissional com a sociedade, teremos que reconhecer que ele, antes de ser profissional, é homem. Deve ser comprometido por si mesmo".

Nesse sentido, fica evidente nos relatos dos gestores a questão das dificuldades vivenciadas a partir da falta de formação profissional.

Imagino que as pessoas tenham que estar preparadas para recebê-los [os deficientes intelectuais], entender que cada pessoa tem um nível de desenvolvimento intelectual diferente do outro e estar disponível para entender essas pessoas, que essas necessidades são diferentes. As pessoas têm necessidades diferentes, que diferem de pessoa para pessoa. (G3). 
Reafirma-se nas falas acima que uma barreira significativa está relacionada à formação acadêmica dos profissionais - os gestores entrevistados possuíam formação acadêmica nas áreas de Educação Física, Pedagogia e Psicologia até a data das entrevistas, setembro de 2016 -, pois essa preparação necessita, além do conhecimento, um olhar sensível para acolher a pessoa com deficiência. Dessa forma, o compromisso do profissional está diretamente ligado ao atendimento da pessoa com DI, fortalecendo as palavras de Paulo Freire (1988, p. 21), que assevera: "[...] 0 compromisso só é válido quando está carregado de humanismo, este, por sua vez, só é consequente quando está fundado cientificamente".

Outra ação realizada foi a capacitação de professores para o atendimento a pessoas com deficiência, veiculada na Agência de Notícias da PMC:

\begin{abstract}
A Secretaria de Esporte, Lazer e Juventude - em parceria com a Secretaria da Pessoa com Deficiência - treinou 150 professores de Educação Física para 0 atendimento a pessoas com deficiência e fez busca ativa nas escolas de educação especial da cidade para divulgar a programação disponível. Essa é uma das iniciativas adotadas, desde o início da atual gestão, para incluir cada vez mais pessoas com deficiência nas atividades regulares oferecidas nos espaços públicos de esporte e lazer. Também está sendo oferecido um número mínimo de vagas para pessoas com deficiência em todas as atividades, atitude definida por portaria conjunta das duas secretarias. (CURITIBA, Agência de Notícias, 2015).
\end{abstract}

Com a atuação da SEDPCD, em parceria com a SMELJ, a PMC tomou a iniciativa de promover capacitação para os profissionais que atuam diretamente com esse público e de escutar as necessidades e demandas da população com deficiência e seus representantes dos "bairros" por meio de audiências públicas, o que não garante a efetivação em ações para essa população.

A formação destinada para os professores de Educação Física que atuam diretamente na SMELJ é um avanço, porém considera-se que pessoas com deficiência podem necessitar de serviços em áreas distintas da PMC, como qualquer cidadão, desse modo todos os profissionais demandam ter conhecimento sobre as necessidades de acessibilidade, na ideia de que todos temos o compromisso de incluir, não delegando a responsabilidade apenas aos profissionais que trabalham especificamente com esse público. Como aponta G4: "As políticas públicas devem estar interligadas, não somente na Secretaria $A, B$ ou $C$, de forma que trabalhe a educação, ou o lazer, ou a própria 
pessoa com deficiência; as ações devem ser interligadas". A fala anterior reflete a necessidade de que as políticas públicas sejam interligadas, considerando as áreas de atuação perante a pessoa com deficiência, como a educação ou o lazer (G4).

Nessa perspectiva, a acessibilidade para a pessoa com deficiência intelectual está diretamente ligada a questões atitudinais, de formação e informação das pessoas, como em questões de estratégias e métodos de ensino. Como pontua G6 (grifou-se):

Eu acho que a gente tem alguns serviços direcionados para a pessoa com deficiência intelectual, mas, apesar de a gente fazer campanhas, falta muito as pessoas serem recebidas e respeitadas em qualquer espaço, por exemplo, se uma pessoa com deficiência intelectual quer fazer parte de um grupo de dança, é necessário um trabalho para preparar aquele profissional e o ambiente, para coisas que, na verdade, poderiam partir da própria profissional. Então eu acho que hoje a gente tem diversas alternativas pontuais, mas que ainda são feitas de acordo com a necessidade das pessoas. A gente não tem um ambiente acessível e inclusivo plenamente para as pessoas com deficiência intelectual.

A fala de G6 reflete a necessidade de formação para receber as pessoas com deficiência e tornar o ambiente acessível e inclusivo. Há também questões ligadas à dificuldade de propagar a informação, como se pode constatar adiante:

A principal dificuldade é a falta de informação, que não chega, a não ser
pela escola, e também a dúvida de se nossos profissionais estão
preparados mesmo para esse público; acredito que ainda não. (G1).

Existem várias políticas públicas voltadas para a inclusão: o ônibus, o acesso às escolas especiais; isso é um grande destaque para a cidade de Curitiba, porque, embora o Governo Federal e o Governo Estadual não venham no sentido que vem o Brasil todo de acabar com as escolas especiais, Curitiba mantém as escolas especiais, com classes especiais, salas de recurso, isso é uma vantagem não só para a pessoa com deficiência. (G5).

A informação repassada para as escolas especializadas sobre os programas e atividades realizados pela PMC aponta uma dificuldade para a efetivação de tais práticas fora do tempo escolar e a dúvida de que se os profissionais estão preparados para atender a pessoas com deficiência.

Constatou-se que parte das atividades empreendidas pela SMELJ é realizada no tempo escolar, com participação de estudantes com deficiência oriundos das escolas especializadas, vinculando tais atividades a ações pontuais destinadas a esse público, 
como jogos escolares, festival de dança, jogos paradesportivos, entre outras. Tais eventos acabam por evidenciar a participação exclusiva de pessoas com deficiência e não promover a inclusão com as demais pessoas nos programas da SMELJ destinados aos demais cidadãos.

Dessa forma, o discurso das liberdades humanas e dos direitos, como aponta Milton Santos (2014, p. 19), "tantas vezes proclamado e repetido" e "tantas vezes menosprezado", é o que faz a diferença entre o discurso e a realidade. De fato, existe a realização pela PMC de atividades nomeadas de inclusão para pessoas com deficiência na cidade, contudo ações voltadas apenas à participação de pessoas com deficiência acabam por não incluir, e sim propiciar um espaço de participação exclusiva de pessoas com deficiência.

Entende-se que incluir no lazer é diferente de se realizar atividades de lazer apenas para esse público. Incluir não significa apenas estar no mesmo espaço, mas que o espaço e as pessoas que estejam nele convivam de forma solidária e humana, interagindo com as pessoas com deficiência sem evidenciar suas dificuldades, e sim acolhendo a diversidade de formas de participação. Rechia (2015, p. 57) aponta que "[...] o direito ao lazer mantém-se a partir do diálogo, da parceria, do interesse, da luta, do pacto entre os direitos e deveres, entre cidade e cidadão, visando ao 'conviver' nos grandes centros urbanos".

A divulgação para as escolas especializadas ou que atendem a pessoas com deficiência é importante, pois parte do público-alvo está inserido nelas, entretanto a sociedade desconhece muitos direitos da pessoa com deficiência, como o respeito às vagas, às cotas e à inclusão nos diversos lugares, entre eles os espaços públicos de lazer.

\section{CONSIDERAÇÕES FINAIS}

Consideramos que a "formacional" se enquadra como uma categoria da barreira atitudinal, envolvendo especificamente a atitude do profissional com carência de formação continuada ao se deparar no cotidiano com o atendimento para a pessoa com DI. A inclusão de pessoas com DI nos diversos tempos e espaços públicos pode necessitar de políticas públicas com ações específicas para esses cidadãos, incluindo a acessibilidade aos diversos bens e serviços que a cidade engloba, no sentido de ampliar 
a participação social da pessoa com deficiência para outros tempos e espaços da vida, além dos muros da escola.

Para tanto, aponta-se a necessidade de uma formação continuada dos professores e profissionais que atuam frente aos diversos órgãos e secretarias formando uma rede de apoio na educação, no esporte, no lazer, na saúde e no convívio social, visando atender à pessoa com deficiência em várias dimensões que englobam uma vida com qualidade, podendo usufruir da cidade como qualquer outro cidadão.

A formação do profissional na área do lazer deve levar em conta aspectos interdisciplinares da área, a sensibilidade de encontrar soluções para incluir, considerando a oferta de estruturas adequadas, a soma de conhecimento científico sobre as particularidades de cada indivíduo, com suas necessidades e potencialidades, para usufruir dos bens e serviços ligados ao esporte e lazer na cidade.

Políticas públicas efetivas podem ser uma conquista se forem respeitadas as leis, como a LBI, aliando órgãos públicos e privados, com a parceria das universidades na formação docente com o aporte científico, e principalmente ouvir e dar visibilidade às pessoas com deficiência intelectual e seus familiares, na busca de soluções que efetivem ações concretas para esse público.

Para que aconteça a inclusão de pessoas com DI nos programas e espaços de lazer da cidade, a barreira "formacional" apontada dentro da barreira atitudinal roga ser superada. Os profissionais que atendem a essa população precisam ser qualificados com formação continuada e potencializados com sua dimensão humana com um olhar sensível, para vencer barreiras de informação, atitudinais e de preconceito, nos diversos tempos e espaços da cidade.

\section{REFERÊNCIAS}

AMERICAN ASSOCIATION ON INTELLECTUAL AND DEVELOPMENTAL DISABILITIES - AAIDD, 2010. Disponível em: http://aaidd.org/education/. Acesso em: 10 jan. 2017.

BRASIL. Lei no 13.146, de 6 de julho de 2015. Institui a Lei Brasileira de Inclusão da Pessoa com Deficiência (Estatuto da Pessoa com Deficiência). Diário Oficial da União, Poder Legislativo, Brasília, DF, 7 jul. 2015. 
BRASIL. Resolução no 466, de 12 de dezembro de 2012. Diretrizes e normas regulamentadoras de pesquisas em seres humanos. Diário Oficial [da] República Federativa do Brasil, Poder Executivo, Brasília, DF, 13 dez. 2012.

CERTEAU, M. A invenção do cotidiano: artes de fazer. Petrópolis: Vozes, 2014.

CURITIBA. Agência de Notícias da Prefeitura de Curitiba. Professores são treinados para atender pessoa com deficiência em atividades físicas. 14 jan. 2015. Disponível em: http://www.curitiba.pr.gov.br/noticias/professores-sao-treinados-para-atender-pessoacom-deficiencia-em-atividades-fisicas/35272. Acesso em: 20 jan. 2017.

DUARTE, C.; COHEN, R. Metodologia para diagnóstico de acessibilidade em centros urbanos: análise da área central da cidade do Rio de Janeiro. Gestão \& Conexões, Vitória, v. 3, n. 1, p. 142-146, 2014.

FLICK, U. Desenho da pesquisa qualitativa. Porto Alegre: Artmed, 2009.

FREIRE, P. Criando métodos de pesquisa alternativa: aprendendo a fazê-la melhor através da ação. In: HAGUETTE, T. M. F. (Org.). Metodologias qualitativas na sociologia. 2. ed. Petrópolis: Vozes, 1990. p. 34-41.

FREIRE, P. Educação e mudança. 14. ed. Rio de Janeiro: Paz e Terra, 1988.

GÜNTHER, H.; ELALI, G. A.; PINHEIRO, J. Q. A abordagem multimétodos em estudos pessoa-ambiente: características, definições e implicações. In: CAVALCANTI, S.; ELALI, G. A. (Org.). Temas básicos em psicologia ambiental. Petrópolis: Vozes, 2011. p. 369-396.

HAAG, C. R. Linguagem e deficiência intelectual: apresentação de focos de pesquisa. In: ENCONTRO DA REDE SUL LETRAS, 4., 2016, Palhoça. Anais... Palhoça: Unisul, 2016. p. 197-206.

LEFEBVRE, H. O direito à cidade. São Paulo: Centauro, 2001.

MARCELLINO, N. C. Lazer e humanização. 6. ed. Campinas: Papirus, 2002.

MILLECAMPS, P. Via inclusão: guia prático para capacitar a comunidade ao acolhimento das pessoas com deficiência mental. Casa João Cidade: Câmara Municipal de Motemor-o-Novo, 2010.

MINAYO, M. C. S. (Org.). Pesquisa social: teoria, método e criatividade. 29. ed. Petrópolis: Vozes, 2010.

RECHIA, S. Cidadania e o direito ao lazer nas cidades brasileiras: da fábula à realidade. In: GOMES, C. L.; ISAYAMA, H. F. (Org.). O direito social ao lazer no Brasil. Campinas: Autores Associados, 2015. p. 45-60.

SANTOS, M. O espaço do cidadão. 7. ed. São Paulo: Universidade de São Paulo, 2014. 
THIOLLENT, M. Metodologia de pesquisa-ação. 2. ed. São Paulo: Cortez, 1986.

\section{Vania Lucia Girardi (Brasil, Paraná, Curitiba) \\ Universidade Federal do Paraná (UFPR)}

Doutoranda na linha de pesquisa Linguagem, Corpo e Estética na Educação pela Universidade Federal do Paraná (UFPR), mestra em Educação Física pela UFPR e especialista em Educação Especial pelo Instituto Brasileiro de Pós-Graduação e Extensão (Ibpex) e em Educação Especial Inclusiva pela Faculdade São Braz (FSB). Atualmente é professora da Secretaria de Estado da Educação do Paraná (2005-atual) e pesquisadora do Grupo de Estudos e Pesquisas em Lazer espaço e Cidade (Geplec) - 2004-atual.

Lattes: http://lattes.cnpq.br/5696630638600271.

E-mail: girardivania@gmail.com.

\section{Simone Aparecida Rechia (Brasil, Paraná, Curitiba)} Universidade Federal do Paraná (UFPR)

Pós-Doutora pelo Instituto Nacional de Educação Física da Catalunha (Barcelona, Espanha), doutora em Educação Física pela Universidade Estadual de Campinas (Unicamp) e mestra em Educação pela Pontifícia Universidade Católica do Paraná (PUC/PR). Atualmente é professora adjunta da Universidade Federal do Paraná (UFPR), disciplina de fundamentos do lazer e colaboradora no Programa de Pós-Graduação em Educação Física da UFPR e no Programa de Pós-Graduação em Educação da UFPR. Professora visitante na Universidade de Aveiro, em Portugal, no Departamento de Estudos Culturais. Foi presidente do Colégio Brasileiro de Ciências do Esportes de 2013 a 2017. É líder do Grupo de Estudos e Pesquisa em Lazer, Espaço e Cidade (Geplec).

Lattes: http://lattes.cnpq.br/5265139315424802.

E-mail: simone@ufpr.br.

\section{Aline Tschoke (Brasil, Paraná, Curitiba) \\ Instituto Federal do Paraná (IFPR)}

Doutora e mestra em Educação Física pela Universidade Federal do Paraná (UFPR). Tem experiência na área de Educação Física, com ênfase em lazer. Pesquisadora do Grupo de Estudos e Pesquisas em Espaços lazer e Cidade (Geplec) - 2004-atual. Secretária Estadual do Colégio Brasileiro de Ciências do Esporte - PR, gestão (2011-2012). Coordenadora do Grupo de Trabalho (GT) Lazer e Sociedade do Colégio Brasileiro de Ciências do Esporte (2017-2019). Atualmente professora do Instituto Federal do Paraná (IFPR).

Lattes: http://lattes.cnpq.br/9911980307660544.

E-mail: aline.tschoke@ifpr.edu.br.

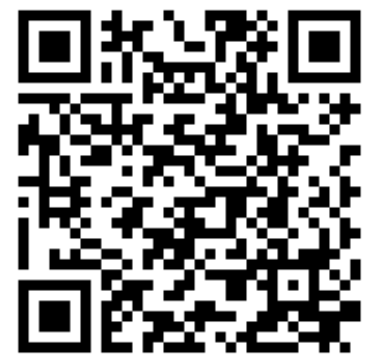

Recebido em 30 de março de 2019.

Aceito em 19 de agosto de 2019.

Educação \& Formação, Fortaleza, v. 5, n. 13, p. 95-112, jan./abr. 2020

DOI: https://doi.org/10.25053/redufor.v5i13.1180

http://seer.uece.br/redufor 